\title{
The analysis of the environmental impact of road traffic in a transport node on the example of the Rondo Rataje roundabout in Poznan
}

\author{
M. Kozak ${ }^{1}$, D. Nijak ${ }^{2}$, K. Kozak², J. Merkisz ${ }^{1}$ \\ \& A. Merkisz-Guranowska ${ }^{1}$ \\ ${ }^{1}$ Poznan University of Technology, Poland \\ ${ }^{2}$ Poznan City Hall, Poland
}

\begin{abstract}
Road transport is one of the main sources of environment pollution. Transport nodes are a particular challenge for the environment and are related to substantial traffic congestion and slow vehicle flow. One of the main transport nodes in the city of Poznan (Poland) is a roundabout known as Rondo Rataje. Within an hour, up to approximately 5500 vehicles pass through this intersection with an average speed of $10-15 \mathrm{~km} / \mathrm{h}$. The paper presents the exhaust emissions and fuel consumption by the vehicles passing through this intersection. These values have been determined based on complex traffic investigations carried out on this intersection, the knowledge of the vehicle structure in Poznan and the use of software for microsimulation of road traffic. The obtained results were subject to further analysis within which the shares of individual vehicle types and emission categories in the total exhaust emissions of individual exhaust components have been identified. The test procedure described in the paper may turn out useful in the evaluation of the influence of the traffic parameters on the exhaust emission level generated by vehicles, thus in the evaluation of various traffic control solutions or infrastructural options.
\end{abstract}

Keywords: traffic microstimulation, simulation analyses, exhaust emissions analysis, transport network assessment.

\section{Introduction}

A substantial growth in the number of motor vehicles observed in Poland in the last couple of years, particularly ever since Poland became the EU member state, 
has led to a significant increase in the traffic intensity and a noticeable deterioration of the traveling conditions in heavily urbanized areas. Unfortunately, the development of the infrastructure does not keep up with the increase in the number of vehicles. The above has become a reason for frequent problems with fluent processing of the generated traffic (congestion). A dynamic advancement of the automotive industry and the number of vehicles in the streets results that in highly urbanized areas the emission from road transport is dominant in the total structure of emissions to the atmosphere. On the national scale, according to the Polish Office for National Statistics [1], road transport is a source of over $30 \%$ of the total emission of $\mathrm{NO}_{\mathrm{x}}$, more than $22 \%$ of the total emission of CO, nearly $25 \%$ of the total emissions of non-methane volatile organic compounds and approx. $18 \%$ of the total emission of dust. According to the data published by European Environment Agency [2], the transport sector in 32 EEA member states in 2009 was responsible for $58 \%$ of the total emission of $\mathrm{NO}_{\mathrm{x}}, 18 \%$ non-methane volatile organic compounds and $30 \%$ of the total emission of CO. The above results in not only a negative impact on the natural environment but also a negative impact on human health and quality of life [3]. For this reason it is necessary to seek solutions that would enable a reduction of the negative impact of the transport on the environment. One of the ways to enable such action (on the stage of design of new transport solutions and optimization of the already existing ones including possible forecasting of potential consequences) is traffic modeling with the use of advanced simulation tools including those enabling advanced environmental simulations. Today, traffic modeling is a fundamental element in the assessment of the consequences of the planned modifications in transport systems in urban areas [4]. Depending on the needs and required accuracy of the reflected phenomena as well as the range of the conducted analyses macrosimulation and microsimulation models are applied (that also sometimes includes intermediate - mesoscopic models).

Analyses of vehicle flow with the conducted experiments were carried out with the use of VISSIM software by PTV - a microscopic traffic flow simulation system enabling a precise analysis of the state of the transport system with a high level of accuracy. The precision of the vehicle flow simulation models mainly depends on the quality of the vehicle modeling including the methodology of vehicle movement through the network [5]. Contrary to less complex models based on a constant speed and a deterministic logic of driving behind the vehicle in front, the VISSIM software features a psychophysical model of driver behavior developed by Wiedemann (1974). The principle behind this model is that the driver of a faster car begins to slow down when he reaches an individual threshold of perception of the vehicle moving before him. Due to the fact that this driver cannot precisely determine the speed of the vehicle in front, the vehicle speed will drop below that of the vehicle in front until another threshold is reached, after which the process of slight acceleration will take place. As a result we obtain an acceleration-deceleration iterative process. Stochastic speed distributions and distance thresholds between the vehicles are a reflection of individual characteristics of the drivers' behavior. The possibility of traffic simulation of different categories of vehicles and high accuracy of modeling of 
the geometry and parameters of the road network leads to a high overall precision of the reproduction of the vehicle traffic.

Within the experiments the following exhaust emission components were subject to analysis: $\mathrm{CO}, \mathrm{CO}_{2}, \mathrm{HC}, \mathrm{NO}_{\mathrm{x}}, \mathrm{PM}$ and, additionally, fuel consumption. The results obtained from the simulation can be generated with different levels of accuracy for each individual vehicle or road portion. They can also be aggregated to a given group of vehicles and totaled as generated by all vehicles. Owing to extensive visualization potential in 2D and 3D graphics it is possible to 'track' a given vehicle together with its characteristics in terms of driving parameters or emissions.

\section{Characteristics of the analyzed intersection}

The Rondo Rataje roundabout is an intermediate solution between a classic roundabout and an intersection with an island in the center. It was created as a result of a search for a multilane version of a roundabout, applicable in the limited space of urbanized areas. The analyzed intersection plays a significant role in the transport system for the city of Poznan and, due to the continuing processes of sub-urbanization, for the Poznan agglomeration. This roundabout is located at one of the main entries to the city from adjacent municipalities and from the A2 expressway. Besides, Rondo Rataje is an important node of public transportation. Due to a very poor technical condition of the overpasses preceding the roundabout on the said eastern entry, heavy-duty vehicle traffic has been limited there. Because of the above and the limitation of the truck traffic in the downtown area heavy traffic is realized only on the north-south axis i.e. along 'Poznan II transportation frame'. The average traffic at the entries to the analyzed intersection as of the moment of conducting the investigations was on the level of approximately 75,000 vehicles/day, which constitutes a significant value that confirms the importance of Rondo Rataje in the transport network of the city of Poznan.

Currently, the entire traffic (trams, buses, cars, pedestrians and cyclists) is realized on the road having three lanes on the ground level. The traffic at the roundabout is controlled with traffic lights. The entries to the roundabout are characterized by the following relations (fig. 1):

- S: one lane - must turn left, one lane must go straight, one lane must go straight or turn right,

- W: one lane - must turn left or go straight, one lane - must go straight, one lane - must turn right,

- E and N: one lane - must turn left or go straight, one lane - must go straight, one lane - must go straight or turn right. 


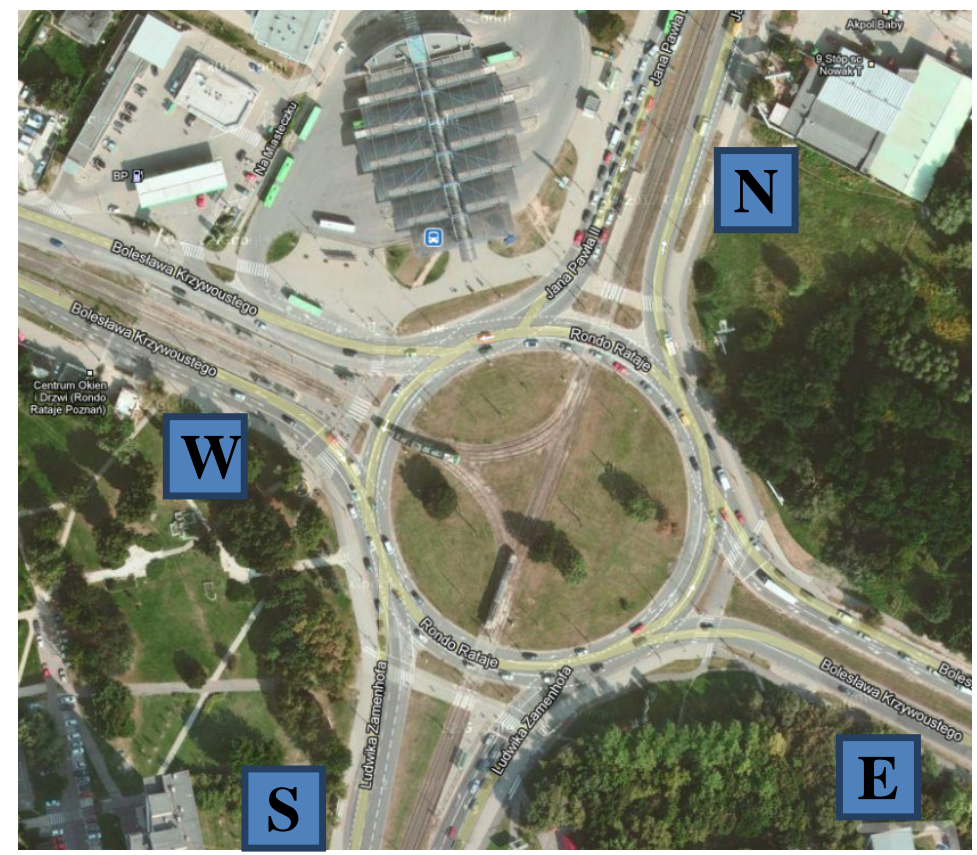

Figure 1: $\quad$ Actual view of the roundabout.

\section{Basic data and assumptions adopted in the traffic simulation}

The traffic analyses for the Rondo Rataje roundabout have been performed in two variants:

- for 2012 - traffic intensity based on the performed measurements

- for 2022 - for which the simulation assumed an increase in the passenger vehicle traffic intensity in the consequent 10 year period by 2,5\% per annum on average and an elimination of minimum EURO3 non-compliant vehicles. The obtained emission levels for the year 2022 are evidently overrated, as we do not know the emission characteristics of vehicles that will be in service in 10 years time.

Analyzing the transport policy of the city of Poznan aiming at reducing heavy traffic in the city limits, particularly in terms of transit traffic, the simulation assumed a preservation of the current heavy traffic intensity in the year 2022 (a drop of the share in the global traffic intensity).

In order to estimate the scale and distribution of the road traffic for 2012 the authors used the results of the traffic intensity measurements for the morning rush hours conducted in May 2012 at the entries and exits of the roundabout, distinguishing the following types of vehicles:

- passenger cars,

- heavy duty trucks, 
- delivery trucks,

- motorcycles,

- buses.

Table 1: $\quad$ Traffic intensity values at the entries and exits from Rondo Rataje [vehicles/hour] in the rush hours - for 2012.

\begin{tabular}{|l|c|c|c|c|c|c|c|c|}
\hline & \multicolumn{2}{|c|}{ Direction S } & \multicolumn{2}{c|}{ Direction N } & \multicolumn{2}{c|}{ Direction E } & \multicolumn{2}{c|}{ Direction W } \\
\cline { 2 - 9 } & Entry & Exit & Entry & Exit & Entry & Exit & Entry & Exit \\
\hline Passenger cars & 1308 & 1196 & 1068 & 906 & 1226 & 1834 & 1226 & 942 \\
\hline Heavy duty trucks & 98 & 90 & 90 & 98 & 10 & 10 & 16 & 6 \\
\hline Delivery trucks & 94 & 114 & 134 & 116 & 114 & 132 & 118 & 106 \\
\hline Motorcycles & 18 & 24 & 42 & 26 & 16 & 22 & 16 & 16 \\
\hline Buses & 32 & 18 & 108 & 36 & 32 & 124 & 26 & 24 \\
\hline
\end{tabular}

It should be noted that the data presented in table 1 do not contain information on the routing of the vehicles entering the roundabout (no information which exit they took). In order to determine the traffic distribution the authors used a macroscopic model of traffic simulation for the city of Poznan and the knowledge on the current traffic limitations at individual entries and exits. Based on the data contained in table 1 and the adopted indexes of traffic growth the values of the traffic intensity were determined at the entries for 10 years (2022).

Because it was necessary to obtain fairly detailed results of the exhaust emission analyses a very important step in the project was to develop a detailed vehicle category structure taking into account the share of vehicles fitted with diesel and gasoline engines, conforming to the individual EURO emission standards within individual vehicle categories. This was done based on the analysis of the database of the Department of Motor Vehicles of the city of Poznan and Central Record of Vehicles and Drivers. Based on such input data the authors defined the required vehicle structure in the VISSIM environment [6]. In order to properly reproduce the routes (selection of the exits by the vehicles) at each entry individual decision points were applied, characteristic of each vehicle class included in the analysis. The traffic intensity at individual road portions was defined using vehicle generators. The duration of each simulation was preset at 7200s and the recording of the analyzed parameters lasted for 3600 s in the interval starting at the 1000th second and ending after 4600s of the simulation. 


\section{Results and analysis of the simulation experiments}

During the simulation (fig. 2) the authors recorded parameters allowing the characterization and evaluation of the analyzed network in terms of traffic conditions on three detail levels:

- Evaluation of the traffic conditions in the analyzed network (time of passage, time of stoppage, length of queue, average speed, average number of stops), accumulated emissions ( $\mathrm{CO}, \mathrm{HC}, \mathrm{NO}_{\mathrm{x}}, \mathrm{PM}, \mathrm{CO}_{2}$ ) and fuel consumption collectively for all vehicles within the network,

- Evaluation in terms of vehicle categories (passenger cars, delivery trucks, heavy duty trucks and buses),

- Detailed evaluation of the characteristics of individual vehicles in the network - enables aggregating results for example in terms of exhaust emission standards within one category of vehicles.

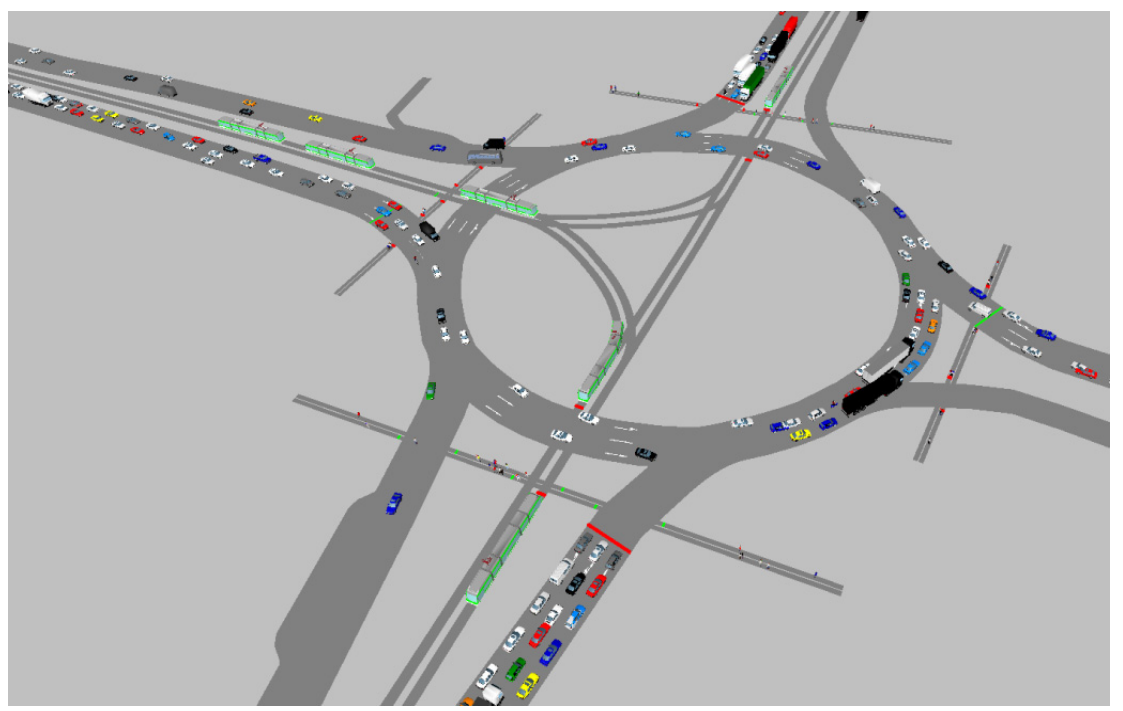

Figure 2: $\quad$ Visualization of the traffic in the Rondo Rataje roundabout.

Analyzing the average speed in the tested fragment of the Poznan road network we should notice that the increase in the traffic intensity results in a deterioration of the value of this index, yet, as results from the simulation data, this is not a very significant influence. We need to remember that using global values in this case without analyzing the outstanding parameters generated during the simulation may lead to erroneous conclusions or wrong decisions. That is why it is important that the parameters describing the condition of the network be analyzed individually i.e. converted into an average per vehicle, unit of length of the traveled distance or time (table 2). 
Table 2: $\quad$ Selected traffic parameters at the Rondo Rataje roundabout during the morning rush hour.

\begin{tabular}{|l|c|c|c|}
\hline Parameter & Unit & $\begin{array}{c}\text { Current state } \\
\text { (2012) }\end{array}$ & $\begin{array}{c}\text { Forecast } \\
\text { (2022) }\end{array}$ \\
\hline $\begin{array}{l}\text { Average speed of the passage } \\
\text { through the roundabout }\end{array}$ & {$[\mathrm{km} / \mathrm{h}]$} & 14.5 & 13.3 \\
\hline $\begin{array}{l}\text { Average delay of the passage as } \\
\text { compared to the optimum passage } \\
\text { through the roundabout }\end{array}$ & {$[\mathrm{s}]$} & 129.5 & 151.6 \\
\hline $\begin{array}{l}\text { Average time of stoppage when } \\
\text { passing through the roundabout }\end{array}$ & {$[\mathrm{s}]$} & 80.4 & 86.7 \\
\hline $\begin{array}{l}\text { Average share of the stoppage } \\
\text { times when passing through the } \\
\text { roundabout }\end{array}$ & {$[\%]$} & 38 & 37 \\
\hline $\begin{array}{l}\text { Average number of stops when } \\
\text { passing through the roundabout }\end{array}$ & {$[1]$} & 12 & 235 \\
\hline $\begin{array}{l}\text { Average length of the queue at the } \\
\text { entry to the roundabout }\end{array}$ & {$[\mathrm{m}]$} & 177 & \\
\hline
\end{tabular}

Analyzing the data contained in table 2 we can see that despite a drop in the average speed of the vehicle passage through the roundabout in the forecast for 2022 by $1.2 \mathrm{~km} / \mathrm{h}$ as against the current state, the average number of stops increased nearly by 4 at a simultaneous extension of the passage time by more than 20s. At the same time the increase in the average length of the queue in the forecast by approximately $60 \mathrm{~m}$ (assuming an average vehicle length of $5 \mathrm{~m}$ ) results that there are, on average, 10 vehicles more in the queue. Based on the data obtained from the performed simulations we may initially determine that the network in the current state operates at the borderline of its throughput and increasing the traffic intensity according to the adopted forecast will lead to a further deterioration of the traffic conditions.

The main aim of the simulation described in the paper was the determination of the influence of the intense traffic in the Rondo Rataje roundabout on the natural environment (the exhaust emission of $\mathrm{CO}, \mathrm{HC}, \mathrm{NO}_{\mathrm{x}}, \mathrm{PM}$ and $\mathrm{CO}_{2}$ ). The emission levels also indirectly provide information on the conditions of the analyzed network. Based on the data on the global emission exhaust values obtained during the simulation (fig. 3) and the number of vehicles that were in the network (or left the network by the moment the data recording was finished) and a total distance traveled by all the vehicles the average specific exhaust emissions were determined in $\mathrm{g} / \mathrm{km}$ (fig. 4). 


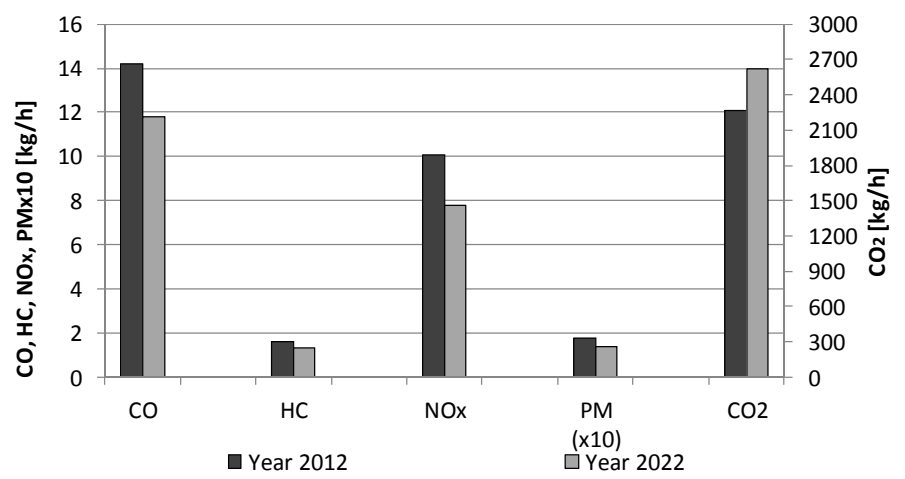

Figure 3: Aggregated hourly emission of individual exhaust components by the vehicles in the Rondo Rataje roundabout (morning rush hours).

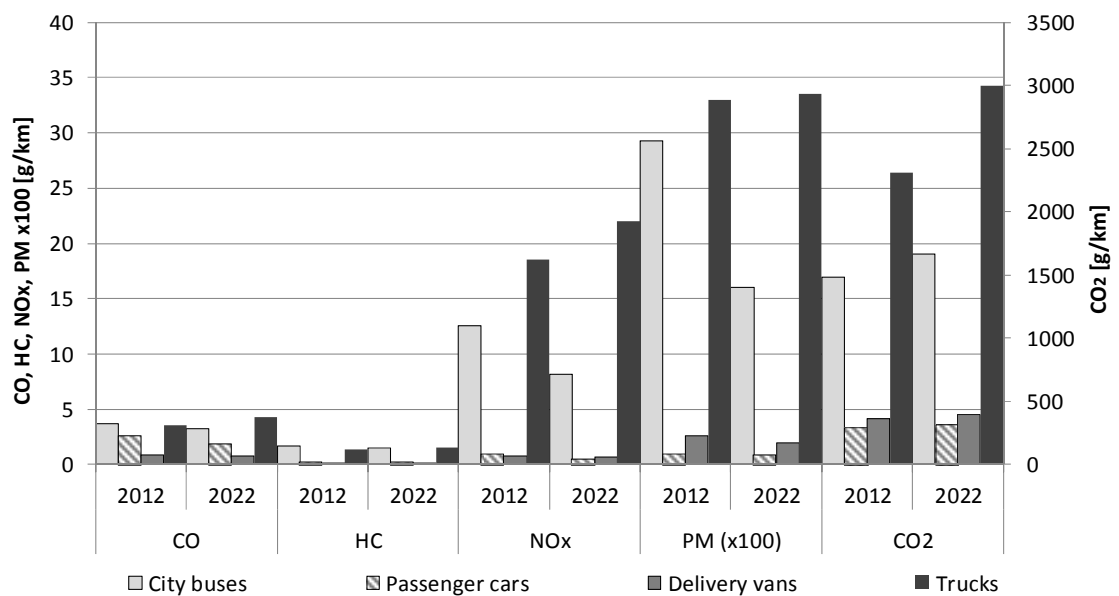

Figure 4: Average specific exhaust emissions $[\mathrm{g} / \mathrm{km}]$ of individual vehicle categories in the Rondo Rataje roundabout in the morning rush hours.

Despite the forecasted increase in the traffic intensity of passenger cars, the exclusion from the entire vehicle group of those vehicles that are not min. EURO 3 complaint results in many cases in a reduction of the emission of the analyzed exhaust components. The assumption of transfer of the total share of the eliminated vehicles in the vehicle structure (from EURO 1 and EURO 2) to the group of vehicle conforming to the EURO3 standard is also important here (in theory the used vehicles were replaced with other used vehicles of similar age in 2012 and 2022). The share of these vehicles with a high level of probability would be distributed over vehicles conforming to the highest emission standards, 
which would further boost the benefits of such changes. We need to remember however that forecasting exhaust emissions is burdened with uncertainty related to future emission standards and vehicle structure (depending on current economic situation) and that is why the data contained in figs 4 and 5 in relation to 2022 should be treated as a indicator of potential trends, showing the benefits resulting from the elimination of vehicles that are the least environment friendly. In reality the benefit rustling from the changes in the vehicle structure (including the appearance of vehicle conforming to the highest, not yet known, emission standards,) should be greater than those forecasted.

The main source of the emission of $\mathrm{CO}$ an $\mathrm{HC}$ in the Rondo Rataje roundabout are passenger cars (fig. 5). It is of vital importance that it is not only the number of passenger vehicles passing through the intersection but also the dominating type of powertrain (gasoline). High emission of $\mathrm{CO}$ and $\mathrm{HC}$ is also facilitated by the engine dynamic operating conditions and in many cases insufficient temperature of the engine and the after treatment system. As for the emission of $\mathrm{NO}_{\mathrm{x}}$ and $\mathrm{PM}$ in the Rondo Rataje roundabout the share of passenger vehicles and heavy-duty vehicles is similar. Despite a much lower number of heavy-duty vehicles this situation results from greater unit emissions [7] and the application of only diesel engines in heavy duty trucks and buses.

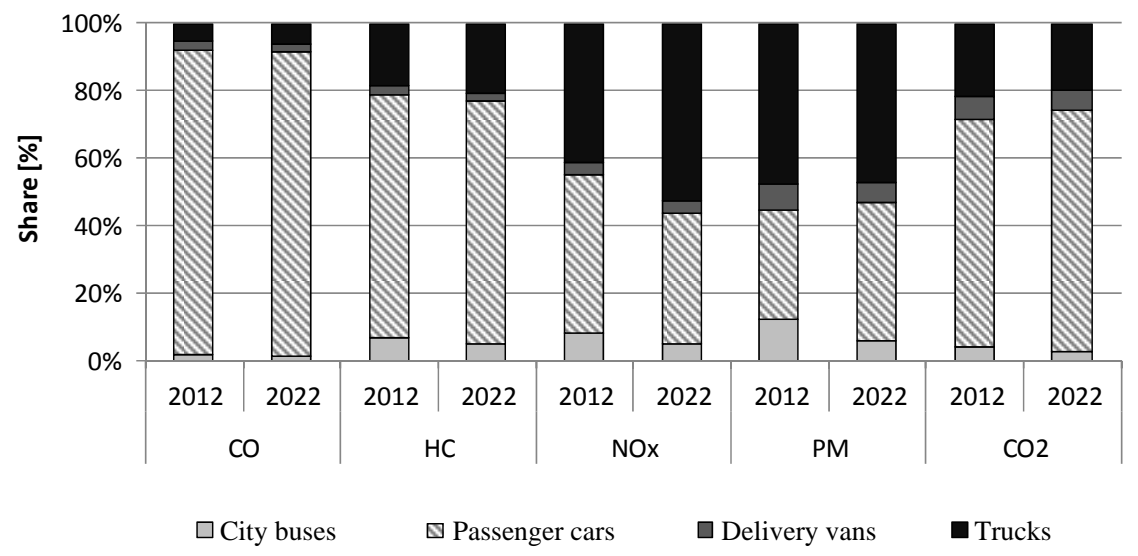

Figure 5: The share of the individual vehicle exhaust emission categories in the exhaust emissions in the Rondo Rataje roundabout.

The data presented in figure 6 indicate that the automotive air pollution is chiefly generated by older vehicles i.e. those conforming to the lowest emission standards only. Passenger vehicles of the Euro 1 standard or older generate more than half of the emission of each of the exhaust components (CO, $\mathrm{HC}, \mathrm{NO}_{\mathrm{x}}$ ). On the other hand, the vehicles conforming to the Euro 4 and higher standards are responsible for only $10 \%$ of the emissions of these exhaust components. In the case of PM the share in the total emission is much more evenly distributed among the individual emission categories. These results from the growing 


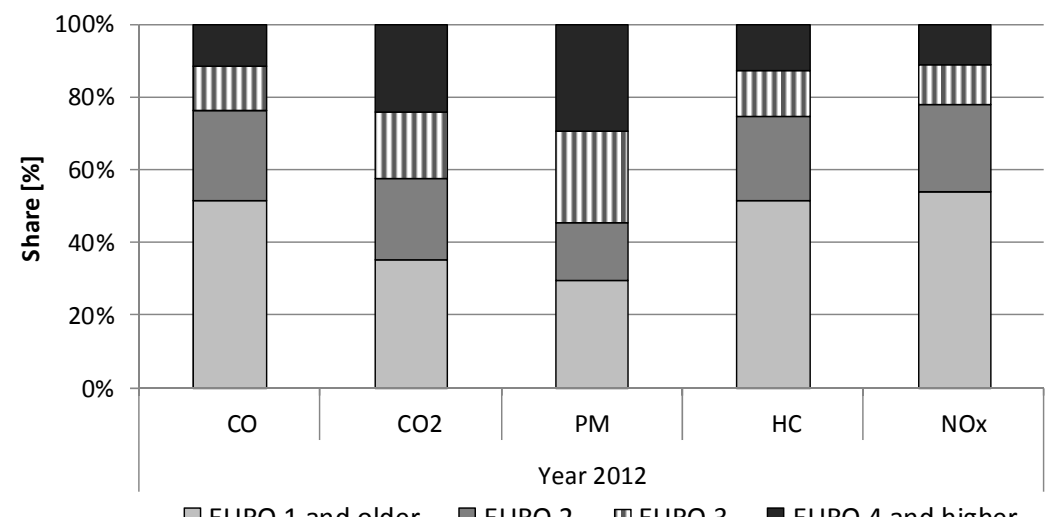

Figure 6: The share of the individual exhaust emission categories in the total exhaust emissions from passenger vehicles in the Rondo Rataje roundabout.

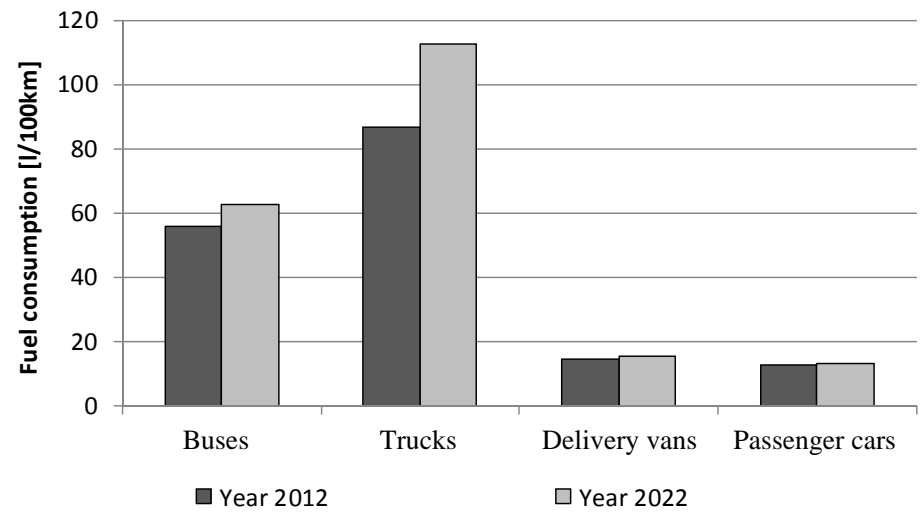

Figure 7: Average fuel consumption of the vehicles in individual vehicle categories in the Rondo Rataje roundabout.

popularity of passenger vehicles fitted with diesel engines whose quantitative share in the low exhaust emission classes was miniscule.

High values of average fuel consumption in the individual vehicle categories, as shown in fig. 7 [1/100 km], are a derivative of a large number of stops per vehicle moving in the analyzed area, a relatively short distance traveled and a significant share of the time of stoppage in the total time of driving through the network. This means that the vehicles cannot move with a steady speed during the simulation. The values of the average fuel consumption presented in fig. 7 should be treated as maximum values for a given node as they were determined 
for a fully loaded network. The highest amount of consumed fuel (fig. 8), and, consequently, the emission of $\mathrm{CO}_{2}$ (fig. 5) is for passenger vehicles, which results from their dominating share in the traffic in the Rondo Rataje roundabout (see table 1).

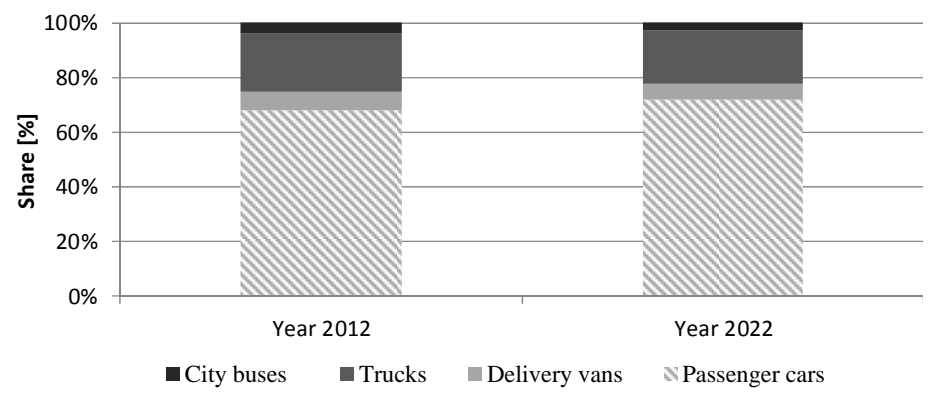

Figure 8: The share of individual vehicle categories in the total fuel consumption by the vehicles in the Rondo Rataje roundabout in the rush hours.

\section{Conclusions}

Road traffic is one of the main sources of environment pollution in large agglomerations. Very important in this problem are the transport nodes where an accumulation of a large number of vehicles (pollution emitters) takes place that under high congestion conditions move with low speed and the traffic flow is reduced. The said conditions facilitate high vehicle unit emissions, which, in connection with a high number of the emission sources, result in the transport nodes being a serious burden for the environment.

The results of the simulation presented in the paper (conducted based on the actual data from the Rondo Rataje roundabout and the city of Poznan) have shown that in the rush hours, when the roundabout absorbs approximately 5500 vehicles per hour, in this transport node the hourly emission of $\mathrm{CO}_{2}$ was approx. 2 tons and other toxic components reached the approx. values as follows: $15 \mathrm{~kg}$ for $\mathrm{CO}, 10 \mathrm{~kg}$ for $\mathrm{NO}_{\mathrm{x}}, 2 \mathrm{~kg}$ for hydrocarbons and $0.2 \mathrm{~kg}$ for PM. The main sources of the gaseous products of combustion $\left(\mathrm{CO}, \mathrm{HC}\right.$ and $\left.\mathrm{CO}_{2}\right)$ are passenger cars but in the case of $\mathrm{NO}_{\mathrm{x}}$ and $\mathrm{PM}$ the share of the passenger and heavy-duty vehicles is similar. Important for the emission level is the age structure of the vehicles, and, consequently, their emission category. Euro 1 or lower standard vehicles are responsible for over a half of the emission of $\mathrm{CO}, \mathrm{HC}$ and $\mathrm{NO}_{\mathrm{x}}$.

The performed simulations confirm a very significant impact of the traffic conditions on the environment pollution generated by motor vehicles. The obtained results also confirm the usefulness of the simulation tools for the environmental analyses and the purposefulness of the application of the analyses in the assessment of scenarios of transport system development. Hence, it is advisable to continue the research works aiming at advancing the methodology 
presented in the paper and the use of this tool particularly in terms of the improvement of the databases on vehicles and their emissions. It is also noteworthy that for high reliability of the conducted simulations it is extremely important to accurately reproduce and calibrate the road network.

\section{Acknowledgement}

The support for this research has been provided by the Polish National Center for Research and Development. Grant no. NR10-0003-10/2011.

\section{References}

[1] Ochrona środowiska 2012, Główny Urząd Statystyczny, Informacje i opracowania statystyczne, Warszawa 2012.

[2] http://www.eea.europa.eu/data-and-maps/indicators/transport-emissions-ofair-pollutants-8/transport-emissions-of-air-pollutants-9.

[3] Walsh, M.P., Global trends in motor vehicle pollution control; a 2011 update. Part 1, Combustion Engines/Silniki Spalinowe no. 2/2011 (145), pp. 107-117.

[4] Żochowska, R. and Karoń, G., Review of Literature on Congestion Effect and Traffic Disturbances in Urban Transport System in the Aspect of Travel Modelling, Zeszyty Naukowo-Techniczne Stowarzyszenie Inżynierów i Techników Komunikacji RP Oddział w Krakowie nr 2(98)/2012, pp. 251276.

[5] Piątkowski, B. and Maciejewski, M., Application of OSM Maps in Creation of a Poznan Agglomeration Network Model for Simulation in MATSim, Zeszyty Naukowo-Techniczne Stowarzyszenie Inżynierów i Techników Komunikacji RP Oddział w Krakowie Nr 2(98)/2012, pp. 163-178.

[6] Kozak, K., Kozak, M., Merkisz, J., Nijak, D. and Wiśniewska, B., The Automotive Situation in Poznan versus other Cities and National Indexes, Archives of Transport/Polish Academy of Sciences no. 3/2012, pp. 341-352.

[7] Merkisz, J., Kozak, M., Nijak, D., Andrzejewski, M., Nowak, M., Rymaniak, Ł. and Ziółkowski, A., The analysis of the emission level from a heavy-duty truck in city traffic, Combustion Engines/Silniki Spalinowe no. 3/2012 (150), pp. 80-88. 